\title{
Adoption of evidence-informed guidelines in prescribing protease inhibitors for HIV-Tuberculosis co-infected patients on rifampicin and effects on HIV treatment outcomes in Uganda
}

Frank Mulindwa ${ }^{1 *}$, Barbara Castelnuovo ${ }^{2}$, Bruce Kirenga ${ }^{1}$, Dennis Kalibbala ${ }^{3}$, Priscilla Haguma ${ }^{1}$, Martin Muddu ${ }^{4}$ and Fred C. Semitala ${ }^{1,4}$

\begin{abstract}
Background: We aimed to determine how emerging evidence over the past decade informed how Ugandan HIV clinicians prescribed protease inhibitors (PIs) in HIV patients on rifampicin-based tuberculosis (TB) treatment and how this affected HIV treatment outcomes.

Methods: We reviewed clinical records of HIV patients aged 13 years and above, treated with rifampicin-based TB treatment while on PIs between1st-January -2013 and 30th-September-2018 from twelve public HIV clinics in Uganda. Appropriate PI prescription during rifampicin-based TB treatment was defined as; prescribing doubled dose lopinavir/ritonavir- (LPV/r 800/200 mg twice daily) and inappropriate PI prescription as prescribing standard dose LPV/r or atazanavir/ritonavir (ATV/r).

Results: Of the 602 patients who were on both Pls and rifampicin, 103 patients (17.1\% (95\% Cl: 14.3-20.34)) received an appropriate PI prescription. There were no significant differences in the two-year mortality $(4.8 \mathrm{vs} .5 .7 \%, P=0.318)$, loss to follow up ( $23.8 \mathrm{vs.} 18.9 \%, P=0.318$ ) and one-year post TB treatment virologic failure rates (31.6 vs. 30.7\%, $P=0.471)$ between patients that had an appropriate PI prescription and those that did not. However, more patients on double dose LPV/r had missed anti-retroviral therapy (ART) days ( $35.9 \mathrm{vs} 21 \%, P=0.001$ ).
\end{abstract}

Conclusion: We conclude that despite availability of clinical evidence, double dosing LPV/r in patients receiving rifampicin-based TB treatment is low in Uganda's public HIV clinics but this does not seem to affect patient survival and viral suppression.

Keywords: Protease inhibitors, Tuberculosis, Drug-drug interactions

*Correspondence: mulindwafrank93@gmail.com

${ }^{1}$ Department of Internal Medicine, Makerere University College of Health Sciences, Kampala, Uganda

Full list of author information is available at the end of the article

\begin{abstract}
Background
Tuberculosis (TB) remains the leading cause of HIV death, accounting for one-third of all HIV deaths worldwide [1]. Integrating HIV and TB treatment is a recommended strategy to reduce mortality and morbidity from both diseases [2, 3]. Evidence-based guidelines have been developed to optimize care for HIV-TB co-infected
\end{abstract}


patients along the entire cascade from prevention [4, 5], diagnosis [6-12], timing for initiation of HIV or TB treatment $[13,14]$ and recognition of drug-drug interactions [15-17]. Translation of this evidence into practice has however, remained variable especially in sub-Saharan Africa where the burden of both diseases is very high [20, 21].

People living with HIV (PLHIV) develop TB at different time points, more often prior to initiation of antiretroviral therapy (ART) [22], but also, during the initial six months of ART as part of the immune reconstitution inflammatory syndrome $[23,24]$. New TB disease has also been observed before initiation or during the course of protease inhibitor (PI) based second line ART [25, 26]. In this case, the management of HIV-TB co-infected patients on second line PI-based ART becomes complicated by drug-drug interactions [27], a scenario more common in resource-limited settings without rifabutin (the recommended substitute for rifampicin in patients on PIs). The World Health Organization (WHO) listed rifabutin as an essential medicine specifically to aid in the programmatic treatment of HIV-TB co-infected patients on PIs in 2009 [28]. However, because of cost, many lowmiddle income countries are yet to avail it in their HIVTB programs more so in sub-Sahara African countries where the HIV-TB burden is highest [26, 29-33].

Rifampicin, a core component of treatment for drug sensitive TB induces the cytochrome P450 (CYP450) enzyme system and the efflux pump $p$-glycoprotein of which PIs are substrates. This interaction between rifampicin and PIs reduces PI trough levels by up to $90 \%[16,19,27,34,35]$. Several pharmacokinetic studies explored how to address the inductive properties of rifampicin by increasing PI doses with variable success. Porte demonstrated that doubling the dose of lopinavir/ritonavir (LPV/r) from $400 / 100 \mathrm{mg}$ twice a day to $800 / 200 \mathrm{mg}$ twice a day achieved therapeutic levels of LPV when co-administered with rifampicin [27]. However, similar adjustments with other PIs including indinavir, saquinavir and atazanavir were associated with unacceptably high rates of adverse drug effects $[16,36$, 37]. The above evidence informed the World Health Organization and Centre for Disease Control guidelines on the use of doubled dose LPV/r in HIV-TB co-infected patients in settings without rifabutin, with emphasis on regular clinical and laboratory monitoring of patients for toxicity [18, 38]. In Uganda, between 2013 and 2019, the recommendation for patients with $\mathrm{TB}$ who were receiving PI-based ART was to use rifabutin instead of rifampicinbased TB treatment and maintain the standard dose of $\mathrm{LPV} / \mathrm{r}$. For patients on atazanavir/ritonavir (ATV/r), the recommendation was to substitute $\mathrm{ATV} / \mathrm{r}$ with standard dose LPV/r [39-41]. However, rifabutin was not available for use in public health facilities in Uganda during those years hence clinicians had to prescribe rifampicin based fixed dose combination TB regimens, which were routinely available.

Following the adoption of routine HIV viral load testing for monitoring HIV care in Uganda in 2015, the numbers of patients on PI based second line ART has increased [42]. This has led to an increase in the number of patients who develop TB while on PI based second line ART. There is therefore a need to optimize care in this group of patients if the third UNAIDS- 90 (viral suppression in 90\% PLHIV on ART by 2020) is to be met [43]. The objective of this study was to determine if health care providers in Uganda conform to WHO guidelines regarding the prescription of PIs when treating HIV-TB co-infected patients on rifampicin-based TB therapy and whether this affects HIV treatment outcomes i.e. death, loss to follow up, missed ART doses and virologic suppression.

\section{Methods \\ Study design, setting and participants}

This was a retrospective cohort study that was conducted between December 2018 and February 2019 in twelve high volume public HIV clinics (each with at least 4500 PLHIV). All the clinics used paper-based patient treatment charts (ART cards) as the primary clinical data entry tool and an open-source electronic medical record (EMR) platform database, the Open Medical Record System $\left(\right.$ OpenMRS $\left.{ }^{\circledR}\right)$, into which ART data was entered. HIV viral load testing was available at all the clinics, with samples processed centrally at the Uganda Ministry of Health (MoH) Central Public Health Laboratory (CPHL). Other tests such as complete blood counts, liver and kidney function tests were performed at the HIV clinics. The study clinics included nine government of Uganda owned facilities (5 Kampala City Council Authority (KCCA) clinics under the capital city management body and 4 regional referral hospital clinics) and three referral clinics that were managed by non-government organizations (Mulago Immunosuppressive syndrome (ISS) clinic, Mbarara ISS clinic and Nsambya Homecare Clinic). All study clinics had HIV and TB care integrated and ART was prescribed by medical officers (general doctors), clinical officers (diploma holding medical assistants) or nurses. For TB treatment, all the health facilities used rifampicin-based fixed dose combination anti- TB drugs during the study years.

The clinics included in this study were selected purposively from the different regions of Uganda i.e. Central, South- Western, West-Nile and Mid-Western regions. These were categorized into two groups according to the level of HIV clinical care offered: group 1 included 
the KCCA HIV clinics headed by general practitioners. Group 2 included Regional Referral Hospital (RRH) HIV clinics. These were also headed by general practitioners but under the referral hospital departments of medicine headed by internists. Group 2 clinics provided inpatient services, specialist clinics at the attached referral hospitals and more advanced diagnostic tests on top of what the group 1 clinics offered i.e. Outpatient ART dispensing, routine laboratory monitoring of patients on ART, HIV testing and counselling, nutritional counselling and care and TB care.

We consecutively included HIV patients $\geq 13$ years diagnosed and treated for TB while on PI- based second line ART between 1st-January-2013 and 30th-September- 2018. A list of eligible patients was obtained from Open MRS. Patients whose paper ART cards were missing and those that were treated for TB for $>1$ year were excluded for possible multi-drug resistant TB treatment.

\section{Definitions}

We defined standard dose LPV/r as LPV/r 400/100 mg taken twice daily (BID), dose adjusted LPV/r as 800/200 mg (BID). Appropriate PI prescription during rifampicin-based TB treatment was defined as prescribing LPV/r 800/200 mg twice daily. Inappropriate PI prescription was defined as prescribing standard dose $\mathrm{LPV} / \mathrm{r}$ or ATV/r during rifampicin- based TB treatment [18] 38.

Virologic failure was defined as a documented HIV viral load $\geq 1000$ copies $/ \mathrm{ml}$ within a year post TB treatment [39-41]. Death was defined as documented death as reported in the ART register. Loss to follow up was defined as; no clinical visit for $\geq 3$ months after missing a scheduled appointment or pharmacy pick-up visit [39-41].

\section{Data collection}

We extracted data from the patients' HIV treatment charts where a TB treatment code 3 or 4 was used to indicate that the patient was on TB treatment during particular clinic visits. This code however did not specify the TB site. Data extracted included; sex, age, weight and functional status at start of TB treatment, duration on PIbased ART before start of TB treatment, ART adherence during TB treatment (measured by pill counts), number of liver function tests done during HIV-TB treatment and the cadre of health worker who prescribed ART at the start of TB treatment. The outcome measurements collected included: the PI prescribed and whether or not dose adjustment was made for LPV/r-based ART at the start of TB treatment, viral load results within a year post TB treatment completion, missed ART doses during TB treatment and two-year post TB treatment initiation date follow up status (alive in care, lost to follow up, dead or transferred out).

All data collected from the electronic medical record were double checked for accuracy using the hard copy treatment charts which were the primary data collection tools during routine clinical care.

\section{Statistical analysis}

Continuous data were summarized as medians with interquartile ranges, while categorical data was summarized as frequencies and percentages. Chi-square test was used to compare baseline clinical and demographic characteristics of patients who had an appropriate PI prescription while on rifampicin-based TB treatment and those that did not.

The overall proportion of patients with appropriate PI prescriptions while on rifampicin-based TB treatment was calculated. It was also represented on a trend line graph for each year from 2013 to 2018 by clinic type. Bivariate and multivariate logistic regression was performed to determine factors associated with inappropriate PI prescription with the following variables: cadre of health care workers prescribing ART (doctor, nurse, clinical officer), clinic cluster, age (stratified in $<25$, and then in 10 years increment), weight (stratified by weight brackets used to determine the number of fixed dose combination anti-TB pills) and duration on protease inhibitor before TB treatment was initiated treatment. Variables with a $\mathrm{p}$ value $\leq 0.2$ in the adjusted analysis were included in the final model.

We also used chi- square test to compare the proportions of HIV treatment outcomes in both patient groups. The analysis was done using STATA version 14.0 (STATA Corp., Texas, USA).

\section{Results}

We evaluated electronic medical records of 671 PLHIV who were concurrently treated with protease inhibitors and anti-TB therapy. Of these, 69 patients $(10.2 \%)$ were excluded from the study (3 patients were on TB treatment for longer than one year, while 66 patients had their ART treatment charts missing). Of the remaining 602 patients, $248(41.2 \%)$ had a two year follow up status at the time of data collection (had been treated for TB between 1stJanuary 2013 and 28th-February 2017) and 218 (36.2\%) had a documented viral load result within a year of completion of TB treatment (Fig. 1).

\section{Baseline demographic and clinical characteristics}

More than half of the patients 314, (52.16\%)) were male, with a majority $(498,82.72 \%)$ from Regional Referral Hospital HIV clinics and 104 patients $(17.28 \%)$ from KCCA clinics. The median age (IQR) was 35 [16, 26-42] 


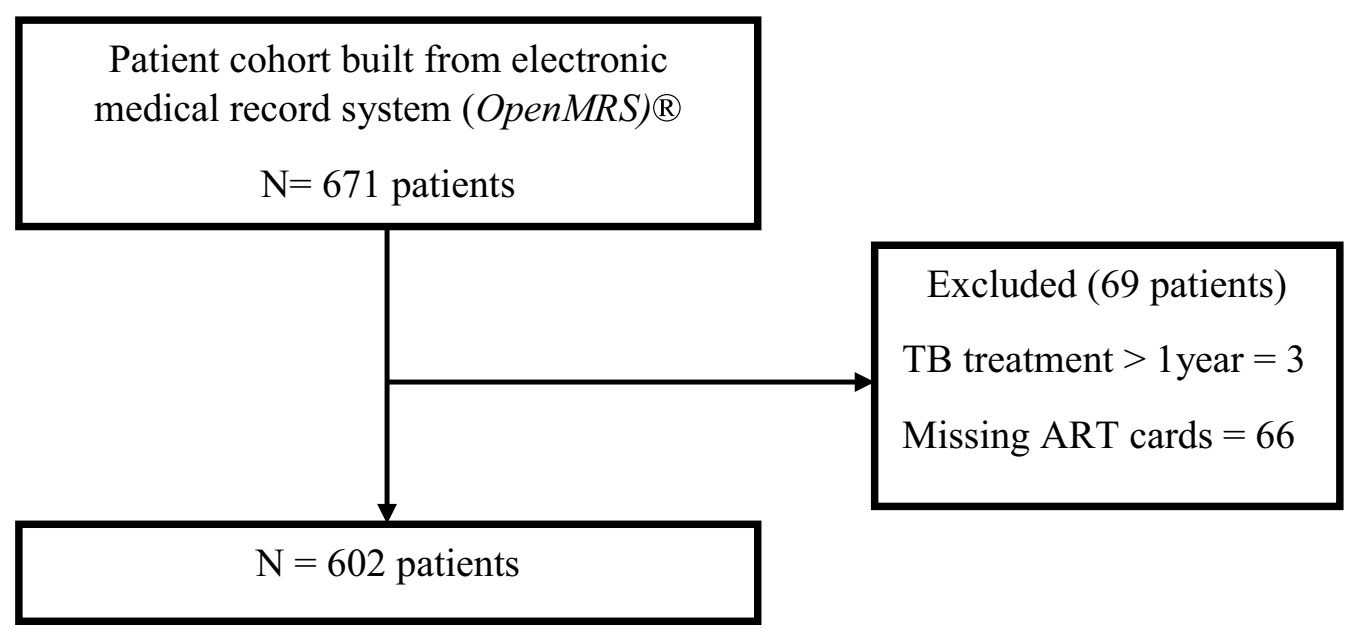

Fig. 1 Study enrollment schema for study patients

years. The median (IQR) time the patients were on a PIbased therapy, before initiation of TB treatment, was $7.1(0-24.6)$ months. Nearly a third of the patients (185, $30.73 \%)$ started the PI-based ART regimens on the same day as for the TB treatment. Half of the patients, 303 (50.33\%) weighed 40-54 $\mathrm{kg}$ and therefore qualified for 3 fixed dose combination TB pills per day. This was followed by the $55-70 \mathrm{~kg}$ weight range $(198,32.89 \%)$ corresponding to 4 fixed dose combination TB pills per day as recommended by the Uganda Ministry of Health [44]. 71 patients $(11.79 \%)$ had at least one liver function test done during TB therapy and 459 (76.25\%) patients had $\geq 95 \%$ reported ART adherence during TB therapy (Table 1).

\section{PI prescription during rifampicin-based TB treatment}

Of the 602 patients who were taking both PIs and rifampicin-based TB therapy, 103 (17.1\% (95\% CI: 14.320.34)) had an appropriate PI prescription. Of the 499 patients that had inappropriate PI prescriptions, 223 patients (37\% (95\% CI: 33.26-40.99)) had a prescription of ATV/r and 276 (45.9\% (95\% CI: 41.89-49.86)) a prescription of standard dose LPV/r. Doctors and nurses were less likely to prescribe protease inhibitors inappropriately (OR: $0.26,95 \%$ CI: $0.15-00.46$, OR: 0.35 , 95\% CI: $0.18-00.71$ respectively, $P<0.001)$ as compared to clinical officers. However, there was no difference in prescription by clinic level, patients' age or weight, and duration on PI (Table 2).

\section{HIV treatment outcomes}

More PLHIV in the appropriate PI prescription group had missed ART days determined by pill counts as compared to those who received inappropriate PI prescriptions ( 35.9 vs. $21 \%, P=0.001)$. There were no significant differences in the two-year follow up outcomes i.e. mortality and loss to follow up between patients that received double dose $\mathrm{LPV} / \mathrm{r}$ and those that did not (4.8 vs. $5.7 \%$, 23.8 vs. $18.9 \%, P=0.318$ respectively). Of the 218 patients with a viral load done within 1-year post TB treatment end date and results documented, there was no significant difference in the rates of virologic failure in the appropriate PI prescription group and inappropriate PI prescription group (31.6 vs. $30.7 \%, P=0.471$ ) (Table 3 ).

\section{Discussion}

In this retrospective cohort study, we assessed how emerging evidence over the past decade informed Ugandan HIV clinicians' prescription practices for PIs when treating HIV-TB co-infected patients on rifampicinbased TB treatment. We found that less than a fifth (17.1\%) of eligible patients had an appropriate PI prescription during rifampicin-based TB therapy. This may be attributed to the absence of clear national HIV-TB treatment guidelines on using dose adjusted LPV/r as an option in the absence of rifabutin for TB treatment [3941]. Additionally, rifabutin is not provided by the Uganda Ministry of Health TB program and hence not routinely available in public clinics [44]. These observations are currently very relevant given the increasing number of patients on PI- based ART and TB treatment since the introduction of routine universal viral load monitoring in 2015 (Fig. 2).

In this study, we also found that doctors were more likely to appropriately prescribe PIs as recommended, compared to clinical officers. This is expected since doctors receive more clinical training than clinical officers. Not surprising, nurses also prescribed PIs more appropriately as compared to clinical officers. This may 
Table 1 Overall and chi-square test comparative demographic and clinical characteristics of the study patients

\begin{tabular}{|c|c|c|c|c|}
\hline Characteristics & Overall cohort $(n=602)$ & $\begin{array}{l}\text { Appropriate } \\
\text { PI prescription } \\
(n=103)\end{array}$ & $\begin{array}{l}\text { Inappropriate PI } \\
\text { prescription }(n=499)\end{array}$ & $p$-value \\
\hline \multicolumn{5}{|l|}{ Gender n (\%) } \\
\hline Female & $288(47.8)$ & $43(41.7)$ & $245(49.1)$ & 0.174 \\
\hline Clinic level n (\%) & & & & 0.004 \\
\hline Kampala City Council HIV Clinics & $104(17.3)$ & $28(26.9)$ & $76(73.1)$ & \\
\hline Regional Referral HIV clinics & $498(82.7)$ & $75(15.1)$ & $423(84.9)$ & \\
\hline Age at start of TB treatment (years), median (IQR) & $35(26-4)$ & & & 0.033 \\
\hline$<25, \mathrm{n}(\%)$ & $131(21.8)$ & $22(16.8)$ & $109(83.2)$ & \\
\hline $25-34, \mathrm{n}(\%)$ & $165(27.4)$ & $31(18.8)$ & $134(81.2)$ & \\
\hline $35-44, \mathrm{n}(\%)$ & $179(29.7)$ & $29(16.2)$ & $150(83.8)$ & \\
\hline $45-54, \mathrm{n}(\%)$ & $100(16.6)$ & $12(12.0)$ & $88(80.0)$ & \\
\hline $55-64, n(\%)$ & $22(3.7)$ & $9(40.9)$ & $13(59.1)$ & \\
\hline$>64, \mathrm{n}(\%)$ & $5(0.8)$ & 0 & $5(100.0)$ & \\
\hline Number of months on PI before TB therapy, median (IQR) & $7.15(0.0-24.6)$ & & & 0.004 \\
\hline PI and TB treatment started on the same date, n (\%) & $185(30.7)$ & $45(43.7)$ & $140(28.1)$ & \\
\hline 0-6 months, n (\%) & $106(17.6)$ & $22(21.4)$ & $84(16.8)$ & \\
\hline 7-12 months, n (\%) & $56(9.30)$ & $9(8.7)$ & $47(9.4)$ & \\
\hline 13-24 months, $n(\%)$ & $102(16.9)$ & $12(11.7)$ & $90(18.0)$ & \\
\hline$>24$ months, $\mathrm{n}(\%)$ & $153(25.4)$ & $15(14.6)$ & $138(27.7)$ & \\
\hline Weight at start of TB treatment $(\mathrm{kg}) \mathrm{n}(\%)$ & & & & 0.022 \\
\hline$<33$ & $30(5.0)$ & $8(26.7)$ & $22(73.3)$ & \\
\hline $33-39$ & $44(7.3)$ & $9(20.5)$ & $35(79.6)$ & \\
\hline $40-54$ & $303(50.3)$ & $44(14.5)$ & $259(85.5)$ & \\
\hline $55-70$ & $198(32.9)$ & $32(16.2)$ & $16(83.8)$ & \\
\hline$>70$ & $27(4.5)$ & $10(37.0)$ & $17(63.0)$ & \\
\hline \multicolumn{5}{|l|}{ Functional status at start of TB treatment n (\%) } \\
\hline Ambulatory & $91(15.1)$ & $14(15.4)$ & $77(84.6)$ & 0.604 \\
\hline Bedridden & $27(4.5)$ & $4(14.8)$ & $23(85.2)$ & \\
\hline Working & $484(80.4)$ & $85(17.4)$ & $399(82.6)$ & \\
\hline \multicolumn{5}{|l|}{ Number of LFTs done during PI-TB treatment n (\%) } \\
\hline 0 & $531(88.2)$ & 99 (18.6) & $432(81.4)$ & 0.006 \\
\hline$\geq 1$ & $71(11.8)$ & $4(5.6)$ & $67(94.4)$ & \\
\hline \multicolumn{5}{|l|}{ Reported ART adherence during TB treatment n (\%) } \\
\hline$\geq 95 \%$ & $459(76.3)$ & $79(17.2)$ & $380(82.8)$ & 0.805 \\
\hline $85-94 \%$ & $50(8.3)$ & $7(14.0)$ & $43(86.0)$ & \\
\hline$<85 \%$ & 93 (15.5) & $17(18.3)$ & 76 (81.7) & \\
\hline
\end{tabular}

Appropriate PI prescription prescription of LPV/r $800 / 200 \mathrm{mg} \mathrm{BID,} \mathrm{inappropriate} \mathrm{PI} \mathrm{prescription} \mathrm{prescription} \mathrm{of} \mathrm{LPV/r} \mathrm{400/100} \mathrm{mg} \mathrm{BID} \mathrm{or} \mathrm{a} \mathrm{prescription} \mathrm{of} \mathrm{ATV/r,} \mathrm{ART} \mathrm{Anti-}$ retroviral therapy, LFTs Liver function tests, IQR Inter-quartile range

be attributed to the fact that, there has been deliberate task shifting drives in Ugandan HIV clinics to empower nurses to prescribe ART [45, 46]. We however, did not find association between the clinic level and PI prescription despite Regional Referral Hospital HIV clinics being at a higher health care delivery level than the KCCA clinics. This can be attributed to system strengthening efforts offered to KCCA clinics by the President's Emergency Plan for AIDS Relief (PEPFAR) program through the
Infectious Diseases Institute (IDI), one of the implementation partners in Uganda.

This study further found no differences in two-year follow up status and virologic failure rates between patients that had appropriate PI prescriptions and those that did not. We did however find equally high levels of virologic failure in both groups, $31.6 \%$ and $30.7 \%$. This is high compared to a retrospective multicenter Sub-Saharan study of which one site was in Kampala- Uganda, that 
Table 2 Bivariate and multivariate logistic regression for factors associated with inappropriate Pl prescription during rifampicin-based TB treatment

\begin{tabular}{|c|c|c|c|c|}
\hline & Crude Odds ratio ( $95 \% \mathrm{Cl})$ & $P$ value & Adjusted Odds ratio $(95 \% \mathrm{Cl})$ & $P$ value \\
\hline \multicolumn{5}{|l|}{ Cadre of prescribing clinician } \\
\hline Clinical officer & 1 & & 1 & \\
\hline Doctor & $0.22(0.13-0.36)$ & $<0.001$ & $0.26(0.15-0.46)$ & $<0.001$ \\
\hline Nurse & $0.27(0.15-0.47)$ & $<0.001$ & $0.35(0.18-0.71)$ & 0.003 \\
\hline \multicolumn{5}{|l|}{ Clinic level } \\
\hline KCCA & 1 & & 1 & \\
\hline $\mathrm{RRH}$ & $2.08(1.26-4.18)$ & 0.004 & $1.10(0.60-2.03)$ & 0.760 \\
\hline \multicolumn{5}{|l|}{ Age (years) } \\
\hline$<25$ & 1 & & 1 & \\
\hline $25-34$ & $0.87(0.47-1.59)$ & 0.657 & $0.86(0.42-1.76)$ & 0.679 \\
\hline $35-44$ & $1.04(0.56-1.91)$ & 0.889 & $0.97(0.47-2.01)$ & 0.939 \\
\hline $45-54$ & $1.48(0.69-3.16)$ & 0.310 & $1.24(0.52-2.96)$ & 0.629 \\
\hline $55-64$ & $0.29(0.11-0.76)$ & 0.012 & $0.33(0.11-1.02)$ & 0.053 \\
\hline \multicolumn{5}{|l|}{ Weight (kg) } \\
\hline$<33$ & 1 & & 1 & \\
\hline $33-39$ & $1.41(0.47-4.21)$ & 0.534 & $1.10(0.33-3.70)$ & 0.878 \\
\hline $40-54$ & $2.14(0.89-5.10)$ & 0.086 & $1.95(0.71-5.38)$ & 0.197 \\
\hline $55-70$ & $1.88(0.77-4.61)$ & 0.164 & $1.78(0.59-5.32)$ & 0.305 \\
\hline$>70$ & $0.62(0.20-1.90)$ & 0.402 & $0.49(0.12-1.94)$ & 0.310 \\
\hline \multicolumn{5}{|l|}{ Duration on PI before TB treatment } \\
\hline $\begin{array}{l}\text { Pl and TB treatment started the } \\
\text { same day }\end{array}$ & 1 & & 1 & \\
\hline$<1$ year & $1.35(0.81-2.27)$ & 0.245 & $1.01(0.58-1.77)$ & 0.975 \\
\hline 1 year $-\leq 2$ years & $2.41(1.21-4.80)$ & 0.012 & $1.45(0.69-3.05)$ & 0.322 \\
\hline$>2$ years & $2.96(1.57-5.55)$ & 0.001 & $1.56(0.77-3.16)$ & 0.216 \\
\hline
\end{tabular}

KCCA Kampala City Council Authority, RRH Regional Referral Hospital, inappropriate PI prescription prescription of LPV/r 400/100 mg BID or a prescription of ATV/r

Table 3 Chi square comparative HIV treatment outcomes among the study patients by PI prescription

\begin{tabular}{lll}
\hline & $\begin{array}{l}\text { Appropriate PI prescription } \\
\mathbf{n}(\%)\end{array}$ & $\begin{array}{l}\text { Inappropriate PI prescription } \\
\mathbf{n}(\%)\end{array}$ \\
\hline 2-year post TB treatment HIV clinical outcome $(\mathrm{N}=248)$ & $\mathrm{N}=21$ & $\mathrm{~N}=227$ \\
Alive in care & $13(61.9)$ & $146(64.3)$ \\
Dead & $1(4.8)$ & $13(5.7)$ \\
LTFU & $5(23.8)$ & $43(18.9)$ \\
TO & $2(9.5)$ & $25(11.0)$ \\
Missed ART days during TB treatment, $(\mathrm{N}=602)$ & $\mathrm{N}=103$ & $\mathrm{~N}=499$ \\
None & $66(64.1)$ & $394(79.0)$ \\
Missed & $37(35.9)$ & $105(21.0)$ \\
Closest viral load post TB treatment & $\mathrm{N}=19$ & $\mathrm{~N}=199$ \\
(within 1 year) $(\mathrm{N}=218)$ & & $138(69.4)$ \\
Suppressed & $13(68.4)$ & $61(30.7)$ \\
Virologic failure & $6(31.6)$ & 0.471
\end{tabular}

LTFU loss to follow up, TO Transferred out, Appropriate P/ prescription LPV/r 800/ $200 \mathrm{mg}$ BID, inappropriate P/ prescription prescription of LPV/r $400 / 100 \mathrm{mg} B I D$ or a prescription of ATV/r, ART Antiretroviral therapy

demonstrated $8 \%$ two year virologic failure rates in a PI based ART cohort [47]. The same study demonstrated rifampicin exposure as a risk factor for virologic failure underlying the fact that patients on second line PI based ART co-infected with TB are at a higher risk of treatment failure. It is possible that some of the patients in our 


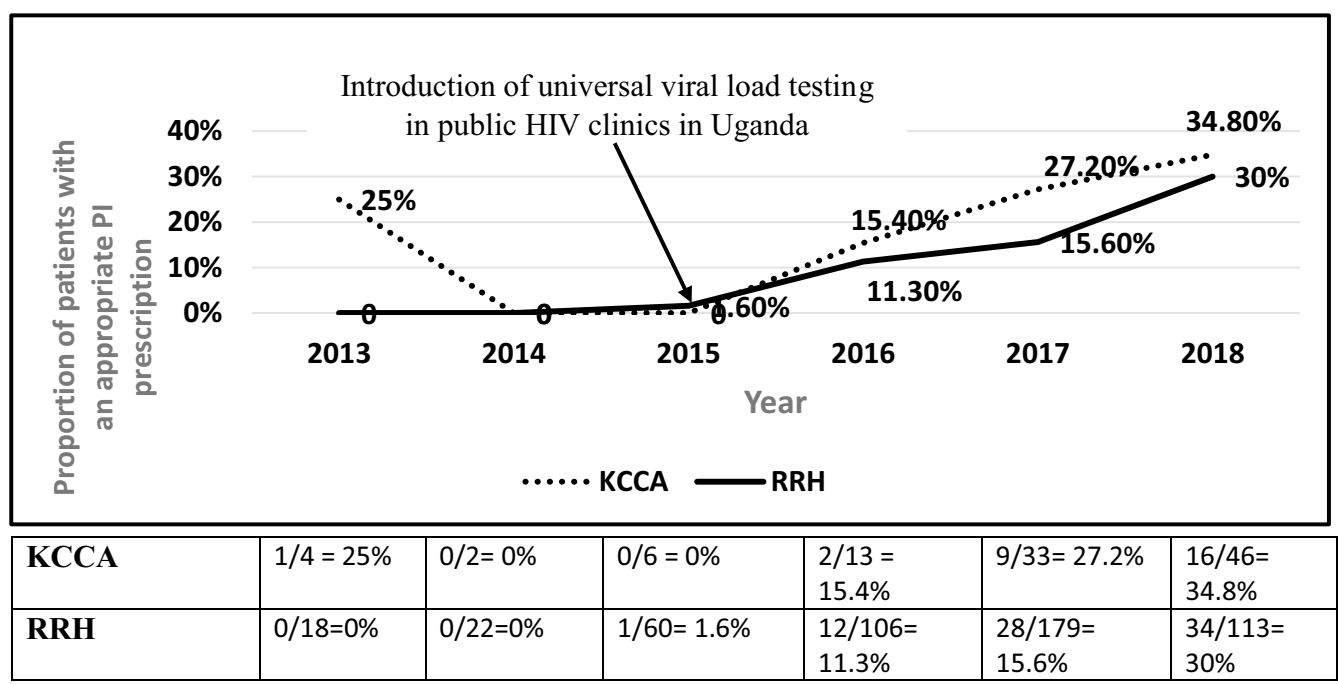

Fig. 2 Trends of proportion of patients with appropriate PI prescription by clinic level and year. KCCA Kampala Capital City Authority, RRH Regional Referral Hospital

analysis developed TB in the first place because of treatment failure while on PIs as was demonstrated in a South African cohort study that showed a high viral load as an independent risk factor for development of TB [48], or the viremia was transient due to the TB infection $[49,50]$. Additionally, it is also possible the $218(36.2 \%)$ patients that got a viral load done within a year post TB treatment are the patients who clinically showed symptoms of treatment failure and hence were prioritized. These reasons could partially account for the markedly high rates of virologic failure in the study group.

Comparatively, a retrospective study in South Africa that compared tolerability and virologic outcomes between patients who were treated with dose-adjusted $\mathrm{LPV} / \mathrm{r}$ to those on standard dose $\mathrm{LPV} / \mathrm{r}$ while on rifampicin also found no difference in virologic suppression between the two groups post TB therapy. One shortcoming of this study was the small sample size of 29 patients [17]. The same study also demonstrated a high proportion of patients developing gastrointestinal and hepatic toxicity in the group that received double dosed LPV/r with an increased need for treatment discontinuation ( $47 \%$ vs. $7 \%$; $p=0.035)$. Another pharmacokinetic study in Brazil that evaluated the interaction between LPV/r 800/200 mg BID and rifampicin demonstrated that most patients attained therapeutic levels of LPV but notably and clinically very important, adherence to both TB treatment and PIs was low because of the high pill burden and increased frequency of adverse events [19]. In our study, patients who received appropriate PI prescriptions had more missed ART days as compared to those that did not, suggesting that adherence may have been poorer in this group most likely due to the high pill burden and side effects associated with $\mathrm{LPV} / \mathrm{r}$ dose adjustment. This finding also suggests that while the drug levels are potentially within the therapeutic range in patients with appropriate PI prescriptions, this may be negated by suboptimal adherence [19].

From the study results, we recommend a deliberate training program for HIV health care providers in Uganda with more emphasis on clinical officers on the need for dose adjusting LPV/r among patients on PIbased ART while taking rifampicin- based TB treatment. There should as well be more robust clinical and laboratory follow up in these patients to improve drug adherence as well as effectively monitor for adverse events.

Limitations of this study included the retrospective nature of the analysis and the use of observational data as well as not measuring TB outcomes of the patients. We only had post TB treatment viral load results of a third of the patients which may not be representative of the whole study population. Additionally, we were also not able to compare post TB treatment viral loads with pre-TB treatment viral loads since most patients did not have viral loads done prior or at the start of $\mathrm{TB}$ treatment. Our study had multiple strengths including the fact that it was multi-center and included different regions of the country and therefore likely to be representative. Also, the proportion of missing patient files was acceptable at $9.8 \%(<10 \%)$. 


\section{Conclusion}

Appropriate PI-based ART prescription in patients receiving rifampicin-based TB treatment is low in Uganda's public HIV clinics. This however, did not seem to influence the patient follow up status and virologic suppression.

\begin{abstract}
Abbreviations
ART: Anti-Retroviral Therapy; ATV/r: Atazanavir/ritonavir; CYP450: Cytochrome P450; CDC: Center for Disease Control; CPHL: Central Public Health Laboratory; EMR: Electronic Medical Record system; ISS: Immunosuppressive syndrome; IDI: Infectious Diseases Institute; KCCA: Kampala City Council Authority; LPV/r: Lopinavir/ ritonavir; MoH: Ministry of Health; PEPFAR: Presidential Emergency Fund for AIDS Relief; PIs: Protease Inhibitors; PLHIV: People Living with HIV; $\mathrm{RRH}$ : Regional Referral Hospital; TB: Tuberculosis.
\end{abstract}

\section{Acknowledgements}

We acknowledge the HIV clinic staff in the study clinics that assisted in data collection. We also acknowledge the patients whose clinic data was reviewed and analyzed.

\section{Authors' contributions}

FM- conceptualized, wrote and executed the research protocol. BC, BK, FSsupervised the protocol writing and execution. DK- was the lead data analyst. MM, PH: participated in data analysis. All members participated in the writing of the manuscript. All authors read and approved the final manuscript.

\section{Funding}

This research was supported by 1) Fogarty International Center, National Institutes for Health (grant \#D43TW009771 'HIV co-infections in Uganda: TB, Cryptococcus, and viral hepatitis') 2) DELTAS Africa Initiative, grant \# DEL15-011 to THRiVE-2.

\section{Availability of data and materials}

The datasets used and/or analyzed during the current study are available from the corresponding author on reasonable request.

\section{Declarations}

\section{Ethics approval and consent to participate}

The study was reviewed and approved by the Makerere University School of Medicine Research and Ethics Committee (approval number: 208-112) and the Uganda National Council of Science and Technology (approval number; HS2576). The requirement for informed consent to review the HIV clinic medical records was waivered by the Makerere University School of Medicine Research and Ethics Committee. All methods were performed in accordance with the relevant guidelines and regulations.

\section{Consent for publication}

Not applicable.

\section{Competing interests}

The authors declare that they have no competing interests.

\section{Author details}

${ }^{1}$ Department of Internal Medicine, Makerere University College of Health Sciences, Kampala, Uganda. ${ }^{2}$ Makerere University Infectious Diseases Institute, Kampala, Uganda. ${ }^{3}$ Makerere University- John Hopkins University Collaboration, Kampala, Uganda. ${ }^{4}$ Makerere University Joint AIDS Program, Kampala, Uganda.

Received: 4 January 2021 Accepted: 9 August 2021

Published online: 16 August 2021
References

1. WHO /TB causes 1 in 3 HIV deaths. WHO [Internet]. 2018 [cited 2021 Jan 4]; http://www.who.int/hiv/mediacentre/news/hiv-tb-patient-centredcare/en/. Accessed 4 Jan 2021.

2. Abdool-Karim SS, Abdool-Karim Q, Friedland G, Lalloo U, El-Sadr WM. START project. Implementing antiretroviral therapy in resource-constrained settings: opportunities and challenges in integrating HIV and tuberculosis care. AIDS. 2004;18(7):975-9.

3. World Health Organization. WHO, Policy on collaborative TB/HIV activities. Geneva: World Health Organization; 2012.

4. Dierberg KL, Chaisson RE. Human immunodeficiency virus-associated tuberculosis. Update on prevention and treatment. Clin Chest Med. 2013. https://doi.org/10.1016/j.ccm.2013.02.003.

5. World Health Organization. Guidelines on tuberculosis infection prevention and control. Geneva: World Health Organization; 2019.

6. Dorman SE, Schumacher SG, Alland D, Nabeta P, Armstrong DT, King B, et al. Xpert MTB/RIF Ultra for detection of Mycobacterium tuberculosis and rifampicin resistance: a prospective multicentre diagnostic accuracy study. Lancet Infect Dis. 2018;18(1):76-84.

7. Kumar K, Kon OM. Diagnosis and treatment of tuberculosis: latest developments and future priorities. Ann Res Hosp. 2017;1:1-1.

8. Metcalf T, Soria J, Montano SM, Ticona E, Evans CA, Huaroto L, et al. Evaluation of the GeneXpert MTB/RIF in patients with presumptive tuberculous meningitis. PLOS ONE. 2018;13(6):e0198695.

9. Opota O, Zakham F, Mazza-Stalder J, Nicod L, Greub G, Jaton K. Added value of Xpert MTB/RIF Ultra for diagnosis of pulmonary tuberculosis in a low-prevalence setting. J Clin Microbiol. 2019. https://doi.org/10.1128/ JCM.01717-18.

10. Pandey P, Pant ND, Rijal KR, Shrestha B, Kattel S, Banjara MR, et al. Diagnostic Accuracy of GeneXpert MTB/RIF assay in comparison to conventional drug susceptibility testing method for the diagnosis of multidrug-resistant tuberculosis. PLOS ONE. 2017. https://doi.org/10.1371/journal.pone. 0169798.

11. Shah W. To determine diagnostic accuracy of gene xpert and sputum Ziehl-Neelsen staining taking sputum culture as gold standard. In: European Respiratory Society (ERS); 2016. p. PA2779.

12. WHO | Next-generation Xpert ${ }^{\circledR}$ MTB/RIF Ultra assay recommended by WHO. WHO [Internet]. 2017. http://www.who.int/tb/features_archive/ Xpert-Ultra/en/. Accessed 7 Oct 2020.

13. Blanc F-X, Sok T, Laureillard D, Borand L, Rekacewicz C, Nerrienet E, et al. Earlier versus later start of antiretroviral therapy in HIV-infected adults with tuberculosis. N Engl J Med. 2011;365(16):1471-81. https://doi.org/10. 1056/NEJMoa1013911.

14. Havlir DV, Kendall MA, Ive P, Kumwenda J, Swindells S, Qasba SS, et al. Timing of antiretroviral therapy for HIV-1 infection and tuberculosis. N Engl J Med. 2011;365(16):1482-91. https://doi.org/10.1056/NEJMoa1013 607.

15. Burger DM, Agarwala S, Child M, Been-Tiktak A, Wang Y, Bertz R. Effect of rifampin on steady-state pharmacokinetics of atazanavir with ritonavir in healthy volunteers. Antimicrob Agents Chemother. 2006;50(10):3336-42.

16. Justesen US, Andersen ÅB, Klitgaard NA, Brøsen K, Gerstoft J, Pedersen C. pharmacokinetic interaction between rifampin and the combination of indinavir and low-dose ritonavir in HIV-infected patients. Clin Infect Dis. 2004;38(3):426-9

17. Murphy RA, Marconi VC, Gandhi RT, Kuritzkes DR, Sunpath H. Coadministration of Lopinavir/Ritonavir and Rifampicin in HIV and tuberculosis co-infected adults in South Africa. PLoS ONE. 2012. https://doi.org/10. 1371/journal.pone.0044793.

18. CDC. Managing Drug Interactions in the Treatment of HIV-Related Tuberculosis. 2014

19. Stanis Schmaltz CA, Martins Costa MJ, Cattani VB, Pereira Pinto D, Liporage J, Benjamin A, et al. Pharmacological interaction of Lopinavir/Ritonavir $800 / 200 \mathrm{mg}$ BID and rifampicin in subjects presenting tuberculosis with contraindication for an efavirenz containing antiretroviral regimen. J AIDS Clin Res. 2014. https://doi.org/10.4172/2155-6113.1000358.

20. Vijayan T, Semitala FC, Matsiko N, Elyanu P, Namusobya J, Havlir DV, et al. Changes in the timing of antiretroviral therapy initiation in HIV-infected patients with tuberculosis in Uganda: a study of the diffusion of evidence into practice in the global response to HIV/AIDS. Clin Infect Dis. 2013;57(12):1766-72 
21. World Health Organization. TB-HIV fact sheet. Geneva: World Health Organization; 2018

22. Lawn SD, Brooks SV, Kranzer K, Nicol MP, Whitelaw A, Vogt M, et al. Screening for HIV-associated tuberculosis and rifampicin resistance before antiretroviral therapy using the Xpert MTB/RIF assay: a prospective study. PLoS Med. 2011;8(7):e1001067.

23. Nagu TJ, Aboud S, Mwiru R, Matee Ml, Rao M, Fawzi WW, et al. Tuberculosis associated mortality in a prospective cohort in Sub Saharan Africa: Association with HIV and antiretroviral therapy. Int J Inf Dis. 2017:56:39-44

24. Walker NF, Stek C, Wasserman S, Wilkinson RJ, Meintjes G. The tuberculosis-associated immune reconstitution inflammatory syndrome: recent advances in clinical and pathogenesis research. Curr Opin HIV AIDS. 2018;13(6):512-21.

25. High TB Risk in HIV-Positive Patients on Second-Line Antiretrovirals in Pune, India - CROI Conference [Internet]. https://www.croiconference. org/abstract/high-tb-risk-hiv-positive-patients-second-line-antiretrov irals-pune-india/. Accessed 7 Oct 2020.

26. Health MOF. Ministry of health consolidated guidelines for the prevention and treatment of HIV and AIDS in Uganda. 2020; (February).

27. la Porte CJL, Colbers EPH, Bertz R, Voncken DS, Wikstrom K, Boeree MJ, et al. Pharmacokinetics of adjusted-dose lopinavir-ritonavir combined with rifampin in healthy volunteers. Antimicrob Agents Chemother. 2004:48(5):1553-60.

28. Geneva. 7th Expert Committee on the Selection and Use of Essential Medicines WHO model list of essential medicines application. 2009.

29. Rockwood N, Cerrone M, Barber M, Hill AM, Pozniak AL. Global access of rifabutin for the treatment of tuberculosis-why should we prioritize this? J Int AIDS Soc. 2019. https://doi.org/10.1002/jia2.25333.

30. Of Rwanda R, of Health M. Republic of Rwanda Ministry of Health National Guidelines for Prevention and Management of HIV and STIs. 2016

31. African S. National for the management of HIV in adults, adolescents, children and infants and prevention of mother-to-child transmission. 2020.

32. National Guidelines on the Use of Antiretroviral Therapy for HIV Prevention and Treatment Fifth Edition Government of Lesotho Ministry of Health National Guidelines for HIV \& AIDS Care and Treatment (5th Edition) National Guidelines for HIV \& AIDS Care and Treatment (4th Edition). 2016

33. I National Guidelines for Antiretroviral Therapy-Sixth Edition.

34. Maartens G, Decloedt E, Cohen K. Effectiveness and safety of antiretrovirals with rifampicin: crucial issues for high-burden countries. Antivir Ther. 2009;14(8):1039-43.

35. Rana F, et al. Rifampicin-an overview. IJRPC 2013;3(1):83-87.

36. Haas DW, Koletar SL, Laughlin L, Kendall MA, Suckow C, Gerber JG, et al. Hepatotoxicity and gastrointestinal intolerance when healthy volunteers taking rifampin add twice-daily atazanavir and ritonavir. J Acquir Immune Defic Syndr. 2009;50(3):290-3.

37. Schmitt C, Riek M, Winters K, Schutz M, Grange S. Unexpected hepatotoxicity of rifampin and saquinavir/ritonavir in healthy male volunteers. Arch Drug Inf. 2009;2(1):8-16.

38. World Health Organization. Consolidated guidelines on the use of ARVs. Geneva: World Health Organization; 2016

39. MoH Uganda. Uganda HIV treatment guidelines. 2016.

40. MoH Uganda. Uganda HIV treatment guidelines.

41. MoH Uganda. Uganda HIV treatment guidelines. 2018.

42. Uganda HIV/AIDS Country Progress Report July 2017-June 2018. 2017.

43. UNAIDS. 0-90-90: An ambitious treatment target to help end the AIDS epidemic. 2014

44. Manual for Management and Control of Tuberculosis and Leprosy 3rd edition March 2017-Ministry of Health | Government of Uganda [Internet]. https://www.health.go.ug/cause/manual-for-management-andcontrol-of-tuberculosis-and-leprosy-3rd-edition-march-2017/. Accessed 7 Oct 2020.

45. Babigumira JB, Castelnuovo B, Lamorde M, Kambugu A, Stergachis A, Easterbrook $\mathrm{P}$, et al. Potential impact of task-shifting on costs of antiretroviral therapy and physician supply in Uganda. BMC Health Serv Res. 2009. https://doi.org/10.1186/1472-6963-9-192.

46. World Health Organization. WHO, Task shifting to tackle heatlh worker shortages. Geneva: World Health Organization; 2007.

47. Sarfo FS, Castelnuovo B, Fanti I, Feldt T, Incardona F, Kaiser R, et al. Longer-term effectiveness of protease-inhibitor-based second line antiretroviral therapy in four large sub-Saharan African clinics. J Infect. 2019;78(5):402-8

48. Fenner L, Atkinson A, Boulle A, Fox MP, Prozesky H, Zürcher K, et al. HIV viral load as an independent risk factor for tuberculosis in South Africa: collaborative analysis of cohort studies. J Int AIDS Soc. 2017. https://doi. org/10.7448/IAS.20.1.21327

49. Jones L, Perelson A. Opportunistic infection as a cause of transient viremia in chronically infected HIV patients under treatment with HAART. Bull Math Biol. 2005;67(6):1227-51. https://doi.org/10.1016/j.bulm.2005. 01.006.

50. Sullivan ZA, Wong EB, Ndung'u T, Kasprowicz VO, Bishai WR. Latent and active tuberculosis infection increase immune activation in individuals co-infected with HIV. EBioMedicine. 2015;2(4):334-40.

\section{Publisher's Note}

Springer Nature remains neutral with regard to jurisdictional claims in published maps and institutional affiliations.

Ready to submit your research? Choose BMC and benefit from:

- fast, convenient online submission

- thorough peer review by experienced researchers in your field

- rapid publication on acceptance

- support for research data, including large and complex data types

- gold Open Access which fosters wider collaboration and increased citations

- maximum visibility for your research: over 100M website views per year

At $\mathrm{BMC}$, research is always in progress.

Learn more biomedcentral.com/submissions 